\title{
Simulation Research on Direct Torque Control for Brushless DC Motor
}

\author{
Fu Longfei", Li Yuren, Tian Guanglai, Liang Bo, Zhang Junli
}

Department of Automatics School, Northwestern Polytechnical University, Xi'an 710072, China

fulongfei0725@126.com

Keywords: direct torque control, brushless DC motor, flux linkage, MATLAB

\begin{abstract}
The design requirements of brushless DC (BLDC) motor control system are on the increase high with the continuously broaden application fields of it. This paper presents the direct torque control(DTC) drive scheme for BLDC motor. The rationale of DTC for BLDC motor is analyzed and torque error is directly used to control the inverter states. The magnitude and phase angle of stator flux linkage vector are deduced under the $\alpha-\beta$ axis stationary reference frame. The control algorithm of stator flux linkage and torque is hysteresis control, then the results and flux linkage regulate the inverter. MATLAB simulation results indicate that DTC scheme for BLDC motor has faster speed of torque response and better performance, achieve the purpose.
\end{abstract}

\section{Introduction}

Brushless DC motor (BLDCM) is a kind of permanent magnet motor for the permanent magnet rotor. It has been widely used in various fields because of its high power density, outstanding speed governing performance, high efficiency, and simple structure [1-3]. The essence of motor control is the torque control and the torque ripple is the BLDCM's biggest problems. The commonly used method of torque control is current control, which has slow torque response and large torque ripple $[4,5]$. The method of direct torque control(DTC) torque and flux linkage directly to control current indirectly, avoiding complex coordinate transformation, and it's a new kind of high performance motor drive control technology [6,7].

There are many effort has made in DTC of BLDC field, such as torque control $[3,6,7]$, torque ripple [8], sensor [2,5] and control algorithm [5]. Markadeh[2] presents rotor flux vector position and torque error control the torque and low the torque ripple. Yan [5] proposes a sensorless fuzzy DTC method based on torque error and flux linkage angle. Liu [8] describes the application of DTC to brushless dc drives and presents the torque estimation and expresses the inverter voltage space vectors.

This paper proposed a new DTC based on the rotor torque for BLDCM torque control. The method improve the torque dynamic response speed and reduce the torque ripple, besides, simplify the structure.

\section{The fundamental of direct torque control}

The electromagnetic generated torque of a BLDCM in the stationary $\alpha-\beta$ reference frame, neglecting the influence of mutual coupling, can be expressed as

$$
T_{e}=\frac{3 p}{4}\left[\frac{d \psi_{r \alpha}}{d \theta_{e}} i_{s \alpha}+\frac{d \psi_{r \beta}}{d \theta_{e}} i_{s \beta}\right]
$$

Where $\theta_{e}$ is the electrical angle, $\mathrm{p}$ is the number of poles, $i_{s \alpha}$ and $i_{s \beta}$ are $\alpha$-and $\beta$-axis stator currents, $\psi_{r \alpha}$ and $\psi_{r \beta}$ are $\alpha$-and $\beta$-axis rotor flux linkages, respectively.

$$
\begin{aligned}
& \psi_{r \alpha}=\psi_{s \alpha}-L_{s} i_{s \alpha} \\
& \psi_{r \beta}=\psi_{s \beta}-L_{s} i_{s \beta}
\end{aligned}
$$

where $\psi_{s \alpha}$ and $\psi_{s \beta}$ are $\alpha$-and $\beta$-axis stator flux linkages, $i_{s \alpha}$ and $i_{s \beta}$ are $\alpha$-and $\beta$-axis stator 
currents, respectively. $L_{s}$ is self inductances.

$$
\begin{aligned}
& \psi_{s \alpha}=\int\left(u_{s \alpha}-R i_{s \alpha}\right) d t \\
& \psi_{s \beta}=\int\left(u_{s \beta}-R i_{s \beta}\right) d t
\end{aligned}
$$

where $u_{s \alpha}$ and $u_{s \beta}$ are $\alpha$-and $\beta$-axis stator voltages, respectively. $R$ is winding resistance.

Then, the magnitude and phase angle of stator flux linkage vector can be calculated as

$$
\begin{aligned}
& \psi=\sqrt{\psi_{s \alpha}^{2}+\psi_{s \beta}^{2}} \\
& \theta=\operatorname{arcran} \frac{\psi_{s \beta}}{\psi_{s \alpha}}
\end{aligned}
$$

The schematic of the DTC BLDC motor drive is shown in Fig.1. In the stationary reference frame, the stator flux linkage can be obtained by sampling the stator phase voltages and currents, like formula (4) and(5), the rotor flux linkage can be derivate according to formula (2) and(3). The magnitude and phase angle of stator flux linkage vector can be calculated from formula (6) and(7). The hysteresis controller which is the control algorithm of stator flux linkage and torque for a faster response than PID controller regulates the torque error and the stator flux linkage error, respectively. The inverter works based on the switching signal which is generated by switching table.

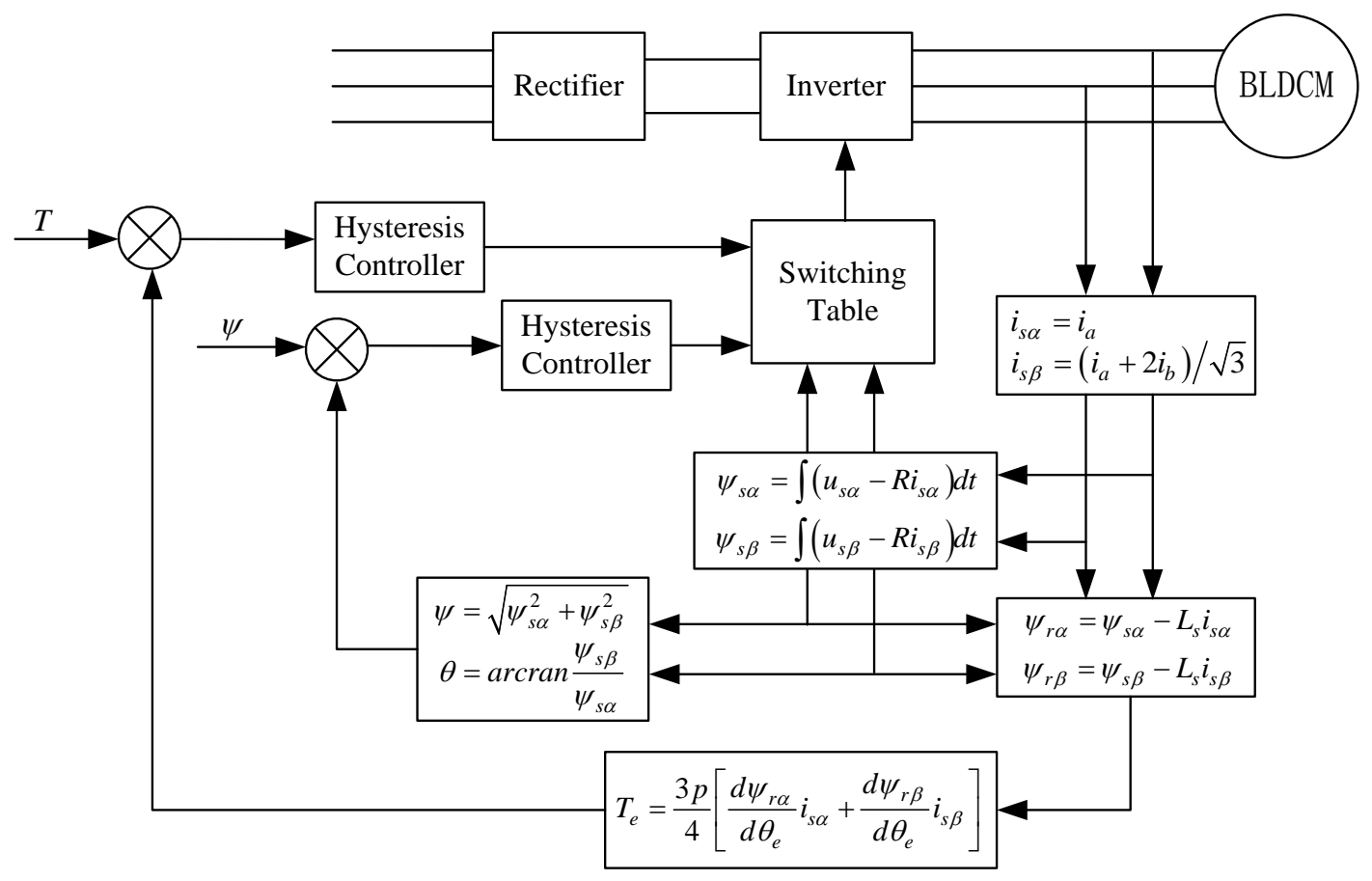

Fig1. Schematic of DTC BLDC motor

\section{Simulation analysis}

MATLAB simulation model was developed to validate the performance of DTC strategy for BLDC motor. The simulation step is 1 microsecond.

Fig. 2 shows the BLDC motor response performance under stable operation at 3000rpm. The simulation condition is that the load torque is varied from $0.2 \mathrm{~N} . \mathrm{m}$ to $3 \mathrm{~N} . \mathrm{m}$ at $0.1 \mathrm{sec}$. As show in fig.1, rotor speed is small fluctuation at the load torque injected, then restore stability gradually. 


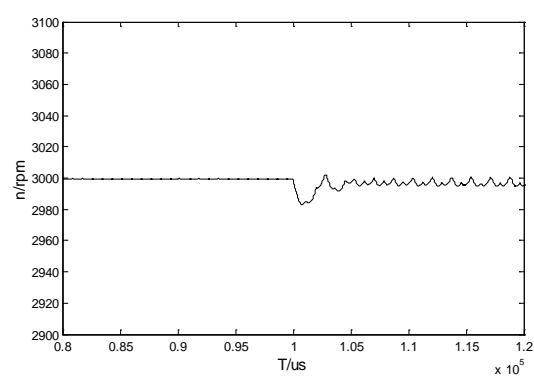

Fig.2 Rotor speed

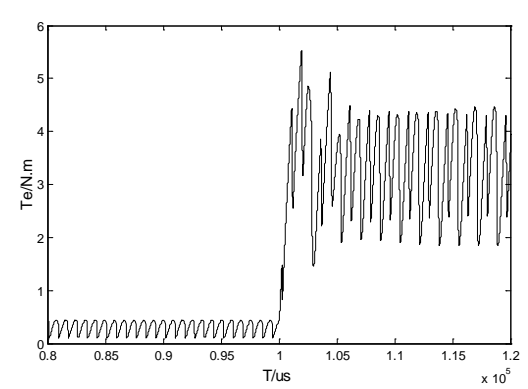

Fig.3 Torque

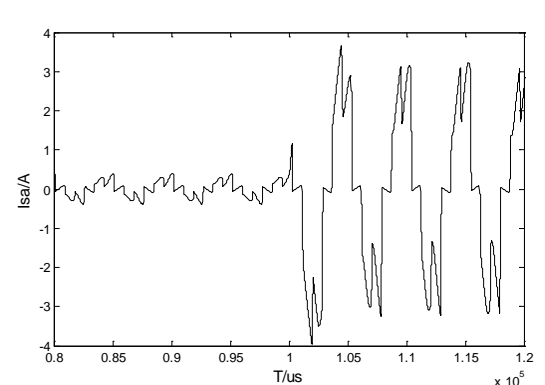

Fig.4 A phase current

Fig. 3 shows the response of electromagnetic torque when the load torque surge at $0.1 \mathrm{sec}$. The torque response time is less than 2ms due to the use of DTC strategy, and as a result, the stator current changes by the load torque. Fig. 4 shows A phase stator current when load torque surge.

\section{Conclusion}

In this paper, the principle of the DTC of the BLDC motor is studied, the generated torque is derivation in the stationary $\alpha$ - $\beta$ reference frame based on the magnitude and phase angle of stator flux linkage vector. Hysteresis controller is applied to regulate the torque error and the stator flux linkage error for its faster response. The proposed approach is validated by MATLAB and the simulation results indicate that the DTC strategy can develop the torque response and improve the performance significantly.

\section{References}

[1] Song Yinghui, Li Yuren, et.al. The Simulation of Brushless Doubly-Fed Machine and Direct Torque Control System[J]. Small \& Special Electrical Machines, 2012,10:45-47.

[2] Markadeh, G.R.Arab;Mousavi, S.I. et.al. Position Sensorless Direct Torque Control of BLDC Motor. Proceedings of the IEEE International Conference on Industrial Technology,2008.

[3] Ozturk, Salih Baris; Toliyat, H.A. Direct Torque Control of Brushless DC Motor with Non-sinusoidal Back-EMF. IEEE/ASME Transactions on Mechatronics,v 16, n 2, p 351-360, April 2011

[4] Masmoudi, Mourad; El Badsi, Bassem; Masmoudi, Ahmed. Direct torque control of brushless DC motor drives with improved reliability. IEEE Transactions on Industry Applications, v 50, n 6, p 3744-3753, Nov, 2014

[5] Yan, Wei-Sheng;Lin, Hai;et.al. Sensorless direct torque controlled drive of brushless DC motor based on fuzzy logic. 2009 4th IEEE Conference on Industrial Electronics and Applications, ICIEA 2009,p 3411-3416.

[6] Zhang Yong, Cheng Xiaohua. Simulation Research on Improved BLDCM Direct Torque Control System[J]. Computer Simulation, v31,n1,p 323-327,2014.

[7] Li guangwei. Study of direct torque control of brushless DC motor[J]. Electric drive Automation, v 33,n 3, p 10-12,2011.

[8] Liu Yong, David Howe. Direct Torque Control of Brushless DC Drives With Reduced Torque Ripple. IEEE TRANSACTIONS ON INDUSTRY APPLICATIONS, v 41, n 2, 2005. 